\title{
The effectiveness of pictogram intervention in the identification and reporting of adverse drug reactions in naïve HIV patients in Ethiopia: a cross-sectional study
}

This article was published in the following Dove Medical Press journal: HIVIAIDS - Research and Palliative Care

\section{Eyob Alemayehu \\ Gebreyohannes' \\ Akshaya Srikanth \\ Bhagavathula ${ }^{1,2}$ \\ Tadesse Melaku Abegaz' \\ Tamrat Befekadu Abebe' \\ Sewunet Admasu Belachew \\ Henok Getachew Tegegn' \\ Sarab M Mansoor ${ }^{3}$ \\ 'Department of Clinical Pharmacy, School of Pharmacy, University of Gondar-College of Medicine and Health Sciences, Gondar, Ethiopia; ${ }^{2}$ Department of Internal Medicine, College of Medicine and Health Sciences, UAE University, AI Ain, United Arab Emirates; ${ }^{3}$ School of Pharmacy, Faculty of Medicine and Health, The University of Sydney, NSW, Australia}

Correspondence: Eyob Alemayehu Gebreyohannes

Department of Clinical Pharmacy, University of Gondar, PO Box 196, Gondar, Amhara, Ethiopia

Tel +25I 920255334

Email justeyob@gmail.com
Purpose: In health communication, pictogram has a comprehensive place to aid attention, memory recall, and promote adherence. This study was conducted to assess whether pictorial intervention would help to identify and improve adverse drug reactions (ADRs) reporting in an antiretroviral therapy (ART) clinic in Northwest Ethiopia.

Patients and methods: A cross-sectional study on ART-naïve HIV-positive patients was conducted from July 2015 to January 2016. The patients were randomly categorized into two groups. Group A was subjected to receive pictorial medication information and a pictogram-enhanced tool to identify and report ADRs, while group B did not receive any pictogram-enhanced tool. Results: A total of 207 ART-naïve HIV-positive patients who were registered for the ART treatment attending Gondar University Hospital ART clinic were included. Bivariate analysis showed that sociodemographic characteristics, such as age, sex, education, employment, and marital status were the main predictors of identifying and reporting ADRs. Males were twice more likely to identify ADRs than females. Univariate analysis revealed that patients assigned to group A showed a significant association with the ability to identify ART medications using pictograms. Patients assigned to group A were more likely to identify lamivudine (OR [95\% CI] $=7.536$ [4.042-14.021], $P \leq 0.001)$, tenofovir (OR [95\% CI] =6.250 [2.855-13.682], $P \leq 0.001)$, nevirapine (OR [95\% CI] $=5.320$ [1.954-14.484], $P=0.001)$, efavirenz $(\mathrm{OR}[95 \% \mathrm{CI}]=3.929$ [1.876-8.228], $P \leq 0.001)$, and zidovudine (OR [95\% CI] =3.570 [1.602-7.960], $P=0.002)$ using pictograms. Patients in group A were 4.3 times more likely to identify diarrhea as an ADR using pictogram compared with group B.

Conclusion: The use of pictorial representation resulted in only slight improvement in identification and reporting of ADRs among naïve HIV-positive patients with limited literacy in Northwest Ethiopia. This representation of ADRs merits further investigation with regard to ADR identification and promoting patients' safety, particularly for HIV-positive patients with limited educational levels.

Keywords: HIV, AIDS, ADR, pictogram, Gondar, Ethiopia, HAART

\section{Introduction}

Universal accessibility and the use of antiretroviral therapy (ART) has changed the fate of HIV-positive patients from life-threatening to a chronic condition by suppressing the viral load and restoring the immune system. ${ }^{1}$ In 2016, 36.7 million people were living with HIV, and about 1 million died of HIV-related illness. ${ }^{1}$ However, adverse drug reactions (ADRs) to these medications remained as an important reason of concern that may compromise the effectiveness of the ART programs. ${ }^{2}$ 
A high number of ADRs related to ART, such as skin rash, anemia, nausea, diarrhea, peripheral neuropathy, and much more, were documented across the world. ${ }^{3-6}$ Patientreported ADRs may differ between developing and developed countries $^{7,8}$ and the incidence of ADRs were more likely to happen in ART-naive patients. ${ }^{9-12}$ Reporting of ADRs during monthly visits to ART clinics provides important implications for switching the medications and minimizing the potential threats. In fact, ADR reporting does not seem simple in ARTnaïve patients unless having some knowledge about the type of ADRs experience during ART initiation. ${ }^{11}$

In health communication, pictogram has a comprehensive place to aid attention, memory recall, and promote adherence to medications. Several health-based pictorial intervention studies demonstrated the benefits of these tools to make patients better understand medical instructions and warnings. ${ }^{13-16}$ Pictograms can help increase patients' knowledge, especially of those who have insufficient knowledge, particularly in countries with low rates of illiteracy. ${ }^{17,18}$ In many countries, pictogram-based intervention is considered to be very limited, and it was applied notably to improve patients' knowledge of medicine information. ${ }^{19-21}$ However, Dowse et al have taken the initiative to develop a validated tool to communicate ART side effects to low-literacy HIV population in South Africa. ${ }^{22}$ The interpretation of these visual images produced was accepted among HIV patients with low literacy. A pictogram-based intervention has been developed to identify and improve ADR reporting among ART-naïve patients with low literacy and having insufficient health information knowledge. Therefore, this study aimed to assess whether a pictogram-based intervention would help to identify and improve ADR reporting in an ART clinic serving HIV patients in Northwest Ethiopia.

\section{Patients and methods Study setting and population}

A cross-sectional study was conducted among ART-naïve patients registered for treatment at ART clinic, Gondar University Hospital (GUH), Northwest Ethiopia. GUH is a 550-bed comprehensive, specialized teaching hospital serving as a referral center for a population of $\sim 7$ million people living in and around Gondar.

Adult ( $>18$ years of age) HIV-positive patients who were newly registered (no longer than 6 months) for first-line ART treatment, visiting GUH for refilling their prescription and were willing to provide written informed consent were included. Hospitalized, severely sick, and patients who were unable to understand the purpose of the study or provide informed consent were excluded.

\section{Survey instrument and content}

A self-administered questionnaire compromising three sections was developed based on a literature review ${ }^{18-24}$ and the research experience of the investigators. To better understand the effect of pictorial representation, two types of questionnaires were developed. Pictorial questionnaire for group A and non-pictorial questionnaire for group B. The content of these questionnaires are quite similar except patients randomized in group A were given pictorial representation to identify their own ART drugs and dosages, and different ADRs.

The questionnaire developed for the two groups, A and $\mathrm{B}$, comprised of three sections. Section 1 includes sociodemographic details (nine items), current comorbidities (one item), and other medical information, such as CD4 cell count, medication history, history of hospitalization, enrollment in ready-to-use therapeutic food program, and information related to discomfort with ART medication. Open-ended questions were used to obtain their responses. Section 2 covers the type of ART medications used and the dosage information. Section 3 includes a list of different ADRs encountered while using ART medications, reported for the last month. For sections 2 and 3, empty spaces were provided to mark them as identified.

\section{Questionnaire validation and reliability}

The developed instrument was translated from English to Amharic (back and forward method), which was done by distributing the questionnaire to six expert faculty members. The Amharic version was used for the study participants. The developed questionnaires (groups A and B) were tested for reliability, psychometric, and internal validation. The internal consistency estimate of the reliability of test scores (Cronbach's alpha) was found to be 0.87 (pictorial) and 0.92 (control), indicating a good construct of the tool. The questionnaires were pilot tested among 20 volunteer patients and 10 senior academicians to assess the content validity. The feedback provided was used to make minor modifications to the questionnaires. The results of the piloting phase were not included. The questionnaire was completed in the waiting room or at the pharmacy refilling room and took an average of 20 minutes to complete. Study investigators (EAG, TMA, TBA, SAB, and HGT) participated in collecting and retrieving the information on a daily basis during the study period.

\section{Study design}

The study was conducted from July 2015 to January 2016. The patients were randomly categorized into two groups based on their ART unique identification number. A total of 234 participants were identified during the study period and 
randomized into group A (117), and group B (117) using concealment published randomization technique. ${ }^{25}$ Participants in group A were subjected to receive pictorial medication information and a pictogram-enhanced tool to identify and report ADRs, while those in group $\mathrm{B}$ did not receive any pictogram-enhanced tool to identify the medications and report ADRs. Both groups received standard care.

\section{Outcome measures}

The primary outcome was to check if there is difference between groups A and B in identifying ART medications, and identifying and reporting ADRs. The secondary outcome was to check if there is any association between sociodemographic characteristics of patients, and identification and reporting of ADRs.

\section{Ethical considerations}

Ethical clearance was obtained from the institutional ethical committee of the University of Gondar-School of Pharmacy. Written informed consent was also obtained from each participant before participating in the study. Confidentiality of participants' personal information was maintained throughout the study. The study was conducted in accordance with the Declaration of Helsinki.

\section{Statistical analysis}

All the statistical data were carried out using SPSS, version 22 (IBM Corporation, Armonk, NY, USA). Descriptive statistics are presented using frequencies and percentages $(\%)$. Bivariate analysis was conducted to identify associations between sociodemographic factors and ADR identification and reporting by the study participants. OR with $95 \%$ CI was used to measure the magnitude and statistical significance of the association. Binary logistic regression was performed to detect differences in the identification of ART medications and reporting ADRs between the two groups. The association was then expressed as OR $(95 \% \mathrm{CI})$ and $P$-value. $P<0.05$ was considered significant.

\section{Results}

Of the 234 patients (117 in either group), 27 were excluded from the final analyses either because they did not give consent to participate $(n=20)$ or returned incomplete questionnaires $(n=7)$, giving a response rate of $88.5 \%$. A total of 207 ART-naïve HIV-positive patients registered for the ART treatment attending GUH ART clinic were included. Participants were randomized into group A $(n=113)$ and group B $(n=94)$. In the study population, males were slightly higher in number than females $(51.2 \%$ vs $48.8 \%)$, with a mean age of 35.15
( $\mathrm{SD} \pm 10.28)$ years. Majority of participants $(75 \%)$ reported receiving a different level of education while the remaining were unable to read or write. Majority of the participants were orthodox Christians (87.92\%), unemployed (66.18\%), and with no sources of income $(73.43 \%)$. The mean CD4 cell count was 426 (SD \pm 178.12 ). The sociodemographic characteristics are presented in Table 1 . There was no statistically significant difference between the two groups $(P>0.05)$. Compared with group $\mathrm{B}$, the most common comorbid condition noticed in group A was community-acquired pneumonia ( $n=14$ vs $n=16$ ), followed by fever/diarrhea ( $n=6$ vs $n=8$ ), pulmonary tuberculosis ( $n=11$ vs $n=7)$, and others $(n=20$ vs $\mathrm{n}=17$ ) (Table 1).

Bivariate analysis of sociodemographic characteristics, such as age, sex, education, employment, and marital status identified sex as the only predictor of identifying and reporting ADRs. Males were twice more likely to identify ADRs than females (Table 2).

Of the ART medication regimens, the zidovudine (AZT)/ lamivudine $(3 \mathrm{TC})$ /nevirapine (NVP) $(\mathrm{n}=44)$ and tenofovir (TDF)/lamivudine/efavirenz $(\mathrm{EFV})(\mathrm{n}=38)$ were the most frequently prescribed medications in both groups $\mathrm{A}$ and $\mathrm{B}$ $(n=29$ and $n=32)$ (Figure 1).

Four different ART regiments were used by the patients. These include the following: AZT-3TC-NVP ( $\mathrm{n}=73,35.3 \%)$, AZT-3TC-EFV ( $n=16,7.7 \%)$, TDF-3TC-EFV ( $n=70,33.8 \%)$, and TDF-3TC-NVP ( $\mathrm{n}=48,23.2 \%)$. AZT-3TC-NVP and TDF3TC-EFV were available as single pills. On the other hand, patients taking either TDF-3TC-NVP or AZT-3TC-EFV were taking two pills (AZT-3TC single pill plus EFV or TDF-3TC plus NVP). Univariate analysis revealed that participants in group A showed a statistically significant association with the ability to identify ART medications using pictograms. Group A participants were more likely to identify 3TC (OR [95\% CI] $=7.536[4.042-14.021], P \leq 0.001), \mathrm{TDF}(\mathrm{OR}[95 \% \mathrm{CI}]=6.250$ [2.855-13.682], $P \leq 0.001), \mathrm{NVP}(\mathrm{OR}[95 \% \mathrm{CI}]=5.320[1.954$ 14.484], $P=0.001), \mathrm{EFV}(\mathrm{OR}[95 \% \mathrm{CI}]=3.929$ [1.876-8.228], $P \leq 0.001$ ), and AZT (OR [95\% CI] =3.570 [1.602-7.960], $P=0.002$ ) using pictograms. Compared with group $\mathrm{B}$, group A was 4.3 times more likely to identify diarrhea as an ADR by using pictogram. However, no significant association was identified for other ADRs between the groups (Table 3).

\section{Discussion}

Although ADRs to ART medications in HIV-positive patients are well known, there has been limited focus on identification and reporting errors made by patients with low literacy. The results of this study have highlighted the fact that a pictorial representation slightly improved the identification and report- 
Table I Characteristics of study population

\begin{tabular}{|c|c|c|c|}
\hline Characteristics & $\begin{array}{l}\text { Group A, n= I I3 } \\
\text { (\%) }\end{array}$ & $\begin{array}{l}\text { Group B, n=94 } \\
\text { (\%) }\end{array}$ & $\begin{array}{l}\text { Total, } \\
\text { N=207 (\%) }\end{array}$ \\
\hline \multicolumn{4}{|l|}{ Age (years) } \\
\hline $18-29$ & 27 (23.9) & $30(31.9)$ & $57(27.5)$ \\
\hline $30-39$ & $43(38.1)$ & $37(39.4)$ & $80(38.6)$ \\
\hline $40-49$ & $29(25.7)$ & $21(22.3)$ & $50(24.2)$ \\
\hline$\geq 50$ & $14(12.4)$ & $6(6.4)$ & $20(9.7)$ \\
\hline \multicolumn{4}{|l|}{ Sex } \\
\hline Female & $57(50.4)$ & $44(46.8)$ & $101(48.8)$ \\
\hline Male & $56(49.6)$ & 50 (53.2) & $106(51.2)$ \\
\hline \multicolumn{4}{|l|}{ Education } \\
\hline Unable to read or write & $25(22.1)$ & $25(26.6)$ & $50(24.2)$ \\
\hline Primary school & $5 I(45 . I)$ & $34(36.2)$ & $85(4 I . I)$ \\
\hline Secondary school & $32(28.3)$ & $29(30.9)$ & $61(29.5)$ \\
\hline College and above & $5(4.4)$ & $6(6.4)$ & $\mathrm{II}(5.3)$ \\
\hline \multicolumn{4}{|l|}{ Employment } \\
\hline Unemployed & $74(65.5)$ & $63(67.0)$ & $137(66.2)$ \\
\hline Employed & $34(30.1)$ & $27(28.7)$ & $61(29.5)$ \\
\hline Student & $5(4.4)$ & $4(4.3)$ & $9(4.3)$ \\
\hline \multicolumn{4}{|l|}{ Marital status } \\
\hline Single & $45(39.8)$ & $37(39.4)$ & $82(39.6)$ \\
\hline Married & $49(43.4)$ & $41(43.6)$ & $90(43.5)$ \\
\hline Widowed & $7(6.2)$ & $2(2.1)$ & $9(4.3)$ \\
\hline Divorced & $8(7.1)$ & $10(10.6)$ & $18(8.7)$ \\
\hline Separated & $4(3.5)$ & $4(4.3)$ & $8(3.9)$ \\
\hline \multicolumn{4}{|l|}{ Religion } \\
\hline Orthodox Christian & $98(86.7)$ & $84(89.4)$ & $182(87.9)$ \\
\hline Protestant & $\mathrm{I}(0.9)$ & $0(0.0)$ & $\mathrm{I}(0.5)$ \\
\hline Muslim & $13(11.5)$ & $9(9.6)$ & $22(10.6)$ \\
\hline Others & $\mathrm{I}(0.9)$ & $\mathrm{I}(\mathrm{I} . \mathrm{I})$ & $2(1.0)$ \\
\hline \multicolumn{4}{|c|}{ Number of family members with HIV } \\
\hline None & $40(35.4)$ & $39(4 I .5)$ & $79(38.2)$ \\
\hline One & $38(33.6)$ & $24(25.5)$ & $62(30.0)$ \\
\hline Two & $30(26.5)$ & $24(25.5)$ & $54(26.1)$ \\
\hline Three & $5(4.4)$ & $7(7.4)$ & $12(5.8)$ \\
\hline \multicolumn{4}{|c|}{ Average monthly family income (Ethiopian Birr) } \\
\hline No income & $82(72.6)$ & $70(74.5)$ & $152(73.4)$ \\
\hline $100-200$ & - & $4(4.3)$ & $4(1.9)$ \\
\hline $20 I-500$ & $4(3.5)$ & $5(5.3)$ & $9(4.3)$ \\
\hline $50 \mathrm{I}-\mathrm{I}, 000$ & $15(13.3)$ & $9(9.6)$ & $24(11.6)$ \\
\hline$>1,000$ & $12(10.6)$ & $6(6.4)$ & $18(8.7)$ \\
\hline \multicolumn{4}{|l|}{ Current CD4 cell count } \\
\hline Median & 390 & 420 & 399 \\
\hline$<350$ & $42(37.2)$ & $34(36.2)$ & $76(36.7)$ \\
\hline$\geq 350$ & $71(62.8)$ & $60(63.8)$ & $131(63.3)$ \\
\hline \multicolumn{4}{|l|}{ Comorbid conditions } \\
\hline $\begin{array}{l}\text { Community-acquired } \\
\text { pneumonia }\end{array}$ & $14(12.4)$ & $16(17.0)$ & $30(14.5)$ \\
\hline Pulmonary tuberculosis & II (9.7) & $7(7.4)$ & $18(8.7)$ \\
\hline Fever/diarrhea >I month & $6(5.3)$ & $8(8.5)$ & $14(6.8)$ \\
\hline Oropharyngeal candidiasis & $6(5.3)$ & $4(4.3)$ & $10(4.8)$ \\
\hline Wasting syndrome & $4(3.5)$ & $5(5.3)$ & $9(4.3)$ \\
\hline Gastrointestinal symptoms & $3(2.7)$ & $3(3.2)$ & $6(2.9)$ \\
\hline Extrapulmonary tuberculosis & $4(3.5)$ & $2(2.1)$ & $6(2.9)$ \\
\hline Others & $20(17.7)$ & $17(18.1)$ & $37(17.9)$ \\
\hline
\end{tabular}


Table 2 Bivariate associations of sociodemographic factors with identifying and reporting ADRs

\begin{tabular}{|c|c|c|c|}
\hline \multirow[b]{2}{*}{$\begin{array}{l}\text { Sociodemographic } \\
\text { characteristics }\end{array}$} & \multicolumn{2}{|l|}{ ADRs } & \multirow[b]{2}{*}{ OR $(95 \% \mathrm{Cl})$} \\
\hline & $\begin{array}{l}\text { Identified, } n=62 \\
\text { (\%) }\end{array}$ & $\begin{array}{l}\text { Not identified, } n=145 \\
\text { (\%) }\end{array}$ & \\
\hline \multicolumn{4}{|l|}{ Age (years) } \\
\hline $18-29$ & $19(33.3)$ & $38(66.7)$ & 1 \\
\hline $30-39$ & $17(21.2)$ & $63(78.8)$ & $1.5(0.474-4.748)$ \\
\hline $40-49$ & $21(42)$ & $29(58)$ & $0.8 \mathrm{I}(0.258-2.544)$ \\
\hline 50 and above & $5(25)$ & $15(75)$ & $2.172(0.683-6.912)$ \\
\hline \multicolumn{4}{|l|}{ Sex } \\
\hline Female & $23(22.8)$ & $78(77.2)$ & 1 \\
\hline Male & $39(36.8)$ & 67 (63.2) & $1.974(1.073-3.633)$ \\
\hline \multicolumn{4}{|l|}{ Education } \\
\hline Unable to read or write & $15(30)$ & $35(70)$ & $\mathrm{I}$ \\
\hline Primary school & $30(35.3)$ & $55(64.7)$ & $\mathrm{I} .273(0.60 \mathrm{I}-2.697)$ \\
\hline Secondary school & $14(23)$ & $47(77)$ & $0.695(0.297-1.626)$ \\
\hline College and above & $3(27.3)$ & $8(72.7)$ & $0.875(0.204-3.761)$ \\
\hline \multicolumn{4}{|l|}{ Employment } \\
\hline Unemployed & $38(27.7)$ & $99(72.3)$ & $\mathrm{I}$ \\
\hline Employed & $23(37.7)$ & $38(62.3)$ & $\mathrm{I} .577(0.833-2.987)$ \\
\hline Student & $\mathrm{I}(\mathrm{II} . \mathrm{I})$ & $8(88.9)$ & $0.326(0.039-2.692)$ \\
\hline \multicolumn{4}{|l|}{ Marital status } \\
\hline Single & $27(32.9)$ & $55(67.1)$ & I \\
\hline Married & $26(28.9)$ & $64(77.1)$ & $0.828(0.433-1.582)$ \\
\hline Widowed & $3(33.3)$ & $6(66.7)$ & $1.019(0.236-4.388)$ \\
\hline Divorced & $4(22.2)$ & $14(77.8)$ & $0.582(0.175-1.938)$ \\
\hline Separated & $2(25)$ & $6(75)$ & $0.679(0.128-3.59)$ \\
\hline
\end{tabular}

Note: Values in bold font are statistically significant.

Abbreviation: ADRs, adverse drug reactions.

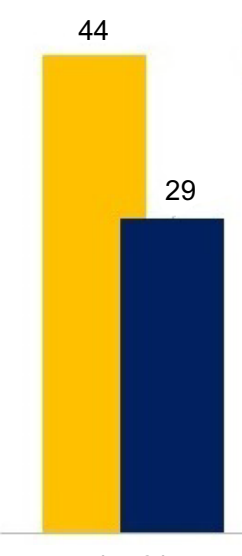

AZT/3TC/NVP

$$
=\text { Group A }
$$$$
\text { - Group B }
$$

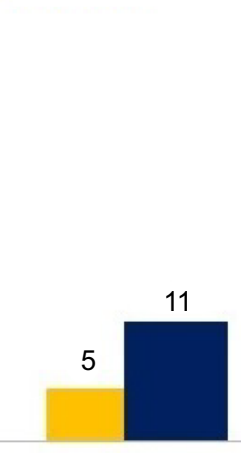

AZT/3TC/EFV
38

32

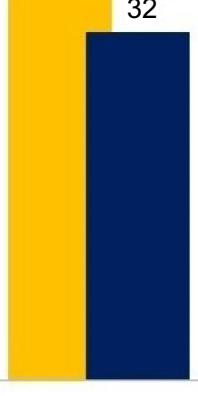

TDF/3TC/EFV
26

22

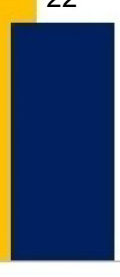

TDF/3TC/NVP

Figure I Frequency of different antiretroviral regimens among study participants.

Abbreviations: AZT, zidovudine; EFV, efavirenz; NVP, nevirapine; TDF, tenofovir; 3TC, lamivudine.

ing of ADRs among ART-naïve patients. Other effects were also observed, including identification of dosing frequency of ART medications and improved ADR reporting. This intervention in a resource-limited setting and considerable reduction of risks, support its potential utility in clinical practice.

Aspects related to research methods support the validity of the results in the present study. For instance, this study utilized validated information materials from another study ${ }^{22}$ that facilitated recall of medicine-related information to culturally and linguistically diverse Ethiopian HIV/AIDS patients with limited literacy skills, which yielded consistent findings. Also, this tool can be used both by patients to report ADRs efficiently and by health care providers as an aid to improve communication, counseling and illustrate HIVtreatment ADRs. It was noted that there are no such tools for assessing ADRs to medications using pictures. However, further investigation with improved research designs such as randomized controlled trials would be of benefit. 
Table 3 Univariate associations of the identification of ART medications and reporting ADRs among the study population

\begin{tabular}{|c|c|c|c|c|}
\hline $\begin{array}{l}\text { Identification of ART } \\
\text { medications and ADRs }\end{array}$ & $\begin{array}{l}\text { Group A, } n=1 \mid 3 \\
N(\%)\end{array}$ & $\begin{array}{l}\text { Group B, } n=94 \\
N(\%)\end{array}$ & OR $(95 \% \mathrm{Cl})$ & $P$-value \\
\hline \multicolumn{5}{|c|}{ Identified ART medications } \\
\hline Lamivudine & $89(78.8)$ & $31(33.0)$ & $7.536(4.042-14.02 I)$ & 0.000 \\
\hline Zidovudine & $31(27.4)$ & $9(9.6)$ & $3.570(1.602-7.960)$ & 0.002 \\
\hline Efavirenz & $39(11.8)$ & II (34.5) & $3.929(1.876-8.228)$ & 0.000 \\
\hline Nevirapine & $26(23.0)$ & $5(5.3)$ & $5.320(1.954-14.484)$ & 0.001 \\
\hline Tenofovir & $7(6.2)$ & $3(3.2)$ & $6.250(2.855-13.682)$ & 0.000 \\
\hline \multicolumn{5}{|l|}{ Identified ADRs } \\
\hline None & $80(70.8)$ & $65(69.1)$ & & 1 \\
\hline Nausea & $9(8.0)$ & $4(4.3)$ & $0.547(0.16 \mathrm{I}-1.857)$ & 0.333 \\
\hline $\begin{array}{l}\text { Vomiting I-2 times a } \\
\text { month }\end{array}$ & $9(8.0)$ & $4(4.3)$ & $0.547(0.16 \mathrm{I}-\mathrm{I} .857)$ & 0.333 \\
\hline Diarrhea & $14(12.4)$ & $4(4.3)$ & $4.308(1.353-14.719)$ & 0.013 \\
\hline Others & II (9.7) & $7(7.4)$ & $0.753(0.287-2.134)$ & 0.633 \\
\hline
\end{tabular}

Note: Values in bold font are statistically significant.

Abbreviations: ADRs, adverse drug reactions: ART, antiretroviral.

The findings of this study are consistent with existing data regarding the use of pictorial illustration and medicationrelated instructions. ${ }^{13,22-24,26,27}$ Pictograms have been found to reinforce and draw attention, particularly for patients with low literacy. ${ }^{28-30}$ Few studies have assessed pictogram intervention in ART patients. ${ }^{13,19,20}$ One study showed that pictograms are well understood in low-literacy ART settings. The overall ability to identify the ART medications (all first-line medications included) was significantly higher in group A $(34.2 \%$ vs $11.8 \%)$. However, most of the ADRs lacked statistical significance, higher number of ADRs were identified and reported from the group A (43 vs 19). Most frequently reported ADRs were nausea and vomiting (18 vs 8 ), and diarrhea (14 vs 4).

Moreover, the pictograms for myalgia, depression, and headache were not identified by group A. This shows that common ADRs experienced by the ART patients are very well reported, and this shows the importance of further investigation of pictogram as a readily interpretable tool to convey a health-related message.

This pictogram has broad applicability for communication and education of patients. Medication ADRs are often not adequately discussed with patients. Hence, these ADRs information can be included along with the written ART medication leaflets only after the pharmacist has counseled the patients, particularly to low-literacy patients. Pictogram could also be used by a pharmacist to educate about ADRs associated with ART and also can aid to support group patient education sessions. Adequate medication-related counseling can help to increase the awareness about possible ADRs and could improve adherence to ART medications.

The study has some limitations. First, the pictorial representation in ART-naïve registered patients attending GUH was randomly evaluated, and the results may differ for follow-up assessment. Furthermore, these pictograms were assessed quantitatively in ART patient, and the causality assessment scales were not used to confirm the reported ADRs. We relied on the participants' honesty while reporting ADRs, hence the participants may over-report or under-report to socially desirable answers that may lead to response bias. The study was conducted in a single center, and most of the participants were from low to middle socioeconomic class, which limits its statistical generalizability and so does not reflect all HIV-positive patients in Ethiopia. It is, therefore, difficult to extrapolate the results to other countries and people living in other settings. Finally, the majority of the participants who received the questionnaire may or may not have experienced ADRs, and this may have possibly skewed the results to look as though there are no significant differences between the two groups.

\section{Conclusion}

The use of pictorial representation resulted in only slight improvement in identification and reporting of ADRs among naïve HIV-positive patients with limited literacy in Northwest Ethiopia. This representation of ADRs provided an insight with the potential implications to identification of ART medications but merits from further investigation with better study designs and larger sample sizes that focus on HIV-positive patients with limited educational levels.

\section{Acknowledgments}

The authors are grateful to all the participants of the study. In addition, the abstract of this paper was presented at the International Society for Pharmacoeconomics and Outcomes Research (ISPOR) 20th Annual European Congress as a poster 
presentation with interim findings. The poster's abstract was published in "Poster Abstracts" in Value in Health, OctoberNovember 2017, Volume 20, Issue 9. In addition, the abstract of this manuscript was also published in the International Journal of Infectious Diseases, August 2018, Volume 73, Supplement, Page 245 as part of the 18th International Congress on Infectious Diseases/XVIII Congreso SADI 2018.

\section{Data sharing statement}

Data and materials can be obtained upon request from the first author or the corresponding author.

\section{Disclosure}

The authors report no conflicts of interest in this work.

\section{References}

1. WHO. Global health observatory (GHO) data. 2015. Available from: http://www.who.int/gho/hiv/en/. Accessed 24 December 2017.

2. Mehta U. Pharmacovigilance: the devastating consequences of not thinking about adverse drug reactions. Contin Med Educ. 2011;29: 247-251.

3. Tedaldi EM, Absalon J, Thomas AJ, Shlay JC, van den Berg-Wolf M. Ethnicity, race, and gender. Differences in serious adverse events among participants in an antiretroviral initiation trial: results of CPCRA 058 (FIRST Study). J Acquir Immune Defic Syndr. 2008;47(4):441-448.

4. Khalili H, Dashti-Khavidaki S, Mohraz M, Etghani A, Almasi F. Antiretroviral induced adverse drug reactions in Iranian human immunodeficiency virus positive patients. Pharmacoepidemiol Drug Saf. 2009;18(9):848-857.

5. Jena A, Sachdeva RK, Sharma A, Wanchu A. Adverse drug reactions to nonnucleoside reverse transcriptase inhibitor-based antiretroviral regimen: a 24-week prospective study. J Int Assoc Physicians AIDS Care (Chic). 2009;8(5):318-322.

6. Srikanth BA, Babu SC, Yadav HN, Jain SK. Incidence of adverse drug reactions in human immune deficiency virus-positive patients using highly active antiretroviral therapy. JAdv Pharm Technol Res. 2012;3(1):62.

7. Kenny J, Musiime V, Judd A, Gibb D. Recent advances in pharmacovigilance of antiretroviral therapy in HIV-infected and exposed children. Curr Opin HIV AIDS. 2012;7(4):305-316.

8. Subbaraman R, Chaguturu SK, Mayer KH, Flanigan TP, Kumarasamy $\mathrm{N}$. Adverse effects of highly active antiretroviral therapy in developing countries. Clin Infect Dis. 2007;45(8):1093-1101.

9. Shet A, Antony J, Arumugam K, Kumar Dodderi S, Rodrigues R, DeCosta A. Influence of adverse drug reactions on treatment success: prospective cohort analysis of HIV-infected individuals initiating firstline antiretroviral therapy in India. PLoS ONE. 2014;9(3):e91028.

10. Jose S, Quinn K, Hill T, et al. Laboratory adverse events and discontinuation of therapy according to $\mathrm{CD} 4(+)$ cell count at the start of antiretroviral therapy. AIDS. 2014;28(9):1333-1339.

11. Kim SH, Gerver SM, Fidler S, Ward H. Adherence to antiretroviral therapy in adolescents living with HIV: systematic review and metaanalysis. AIDS. 2014;28(13): 1945.

12. Ford N, Shubber Z, Pozniak A, et al. Comparative safety and neuropsychiatric adverse events associated with efavirenz use in first-line antiretroviral therapy: a systematic review and meta-analysis of randomized trials. J Acquir Immune Defic Syndr. 2015;69(4):422-429.
13. Wilby K, Marra CA, da Silva JH, Grubisic M, Harvard S, Lynd LD. Randomized controlled trial evaluating pictogram augmentation of HIV medication information. Ann Pharmacother. 2011;45(11): $1378-1383$.

14. van Beusekom MM, Grootens-Wiegers P, Bos MJ, Guchelaar HJ, van den Broek JM. Low literacy and written drug information: informationseeking, leaflet evaluation and preferences, and roles for images. Int $J$ Clin Pharm. 2016;38(6):1372-1379.

15. Chan HK, Hassali MA, Lim CJ, Saleem F, Tan WL. Using pictograms to assist caregivers in liquid medication administration: a systematic review. J Clin Pharm Ther. 2015;40(3):266-272.

16. Vaillancourt R, Pouliot A, Streitenberger K, Hyland S, Thabet P. Pictograms for safer medication management by health care workers. Can J Hosp Pharm. 2016;69(4):286.

17. Sorfleet C, Vaillancourt R, Groves S, Dawson DJ. Design, development and evaluation of pictographic instructions for medications used during humanitarian missions. C Pharm J. 2009;142:82-88.

18. Dowse R, Ehlers MS. The evaluation of pharmaceutical pictograms in a low-literate South African population. Patient Educ Couns. 2001;45(2):87-99.

19. Dowse R, Barford K, Browne SH, Simple BSH. Simple, illustrated medicines information improves ARV knowledge and patient selfefficacy in limited literacy South African HIV patients. AIDS Care. 2014;26(11):1400-1406.

20. Wilby K, Marra CA, da Silva JH, Grubisic M, Harvard S, Lynd LD. Randomized controlled trial evaluating pictogram augmentation of HIV medication information. Ann Pharmacother. 2011;45(11): 1378-1383.

21. Mansoor L, Dowse R. Written medicines information for South African HIV/AIDS patients: does it enhance understanding of co-trimoxazole therapy? Health Educ Res. 2007;22(1):37-48.

22. Dowse R, Ramela T, Barford KL, Browne S. Developing visual images for communicating information about antiretroviral side effects to a low-literate population. Afr J AIDS Res. 2010;9(3):213-224.

23. Yin HS, Dreyer BP, van Schaick L, Foltin GL, Dinglas C, Mendelsohn AL. Randomized controlled trial of a pictogram-based intervention to reduce liquid medication dosing errors and improve adherence among caregivers of young children. Arch Pediatr Adolesc Med. 2008;162(9):814-822.

24. Rajesh R, Vidyasagar S, Varma DM, Sharma S. Design and evaluation of pictograms for communicating information about adverse drug reactions to antiretroviral therapy in Indian human immunodeficiency virus positive patients. J Pharm Biomed Sci. 2012;16:1-11.

25. Kim J, Shin W. How to do random allocation (randomization). Clin Orthop Surg. 2014;6(1):103-109.

26. Choi J. Development and pilot test of pictograph-enhanced breast health-care instructions for community-residing immigrant women. Int J Nurs Pract. 2012;18(4):373-378.

27. Revol M, Vaillancourt R, Pouliot A. Evaluation, validation, and modification of pictograms depicting potential side effects to medication. $J$ Commun Healthc. 2013;6(2):79-89.

28. Moran MB, Frank LB, Chatterjee JS, Murphy ST, Baezconde-Garbanati L. A pilot test of the acceptability and efficacy of narrative and nonnarrative health education materials in a low health literacy population. J Commun Healthc. 2016;9(1):40-48.

29. Durand MA, Alam S, Grande SW, Elwyn G. 'Much clearer with pictures': using community-based participatory research to design and test a picture option grid for underserved patients with breast cancer. $B M J$ Open. 2016;6(2):e010008.

30. Yin HS, Gupta RS, Mendelsohn AL, et al. Use of a low-literacy written action plan to improve parent understanding of pediatric asthma management: a randomized controlled study. J Asthma. 2017;54(9): 919-929. 
HIV/AIDS - Research and Palliative Care is an international, peerreviewed open access journal focusing on advances in research in HIV, its clinical progression and management options including antiviral treatment, palliative care and public healthcare policies to control viral spread. The journal is included in PubMed. The manuscript man-

Submit your manuscript here: https://www.dovepress.com/hivaids---research-and-palliative-care-journal

agement system is completely online and includes a very quick and fair peer-review system, which is all easy to use. Visit http://www.dovepress. com/testimonials.php to read real quotes from published authors. 